\title{
Direito À VIDA: CIDADANIA E SOBERANIA
}

\author{
Anita Guazzelli Bernardes $\star$ \\ Neuza Maria de Fátima Guareschi ${ }^{\star \star}$
}

\begin{abstract}
Resumo
O artigo tem como objetivo analisar a questão do direito à saúde a partir de uma discussão das transformações do discurso da saúde pública para o discurso da saúde coletiva. Essa análise utiliza-se do conceito de público para problematizar o direito à saúde. As metamorfoses do público e sua articulação com a saúde amparam-se na objetivação do público como um dispositivo, conjuntamente com os operadores conceituais de biopoder, verdade e subjetividade. Esta configuração do público é discutida a partir das seguintes linhas: resposta a uma urgência histórica; o tipo de jogo que se estabelece e o conjunto heterogêneo que se conforma.
\end{abstract}

Palavras-chave: Dispositivo. Direito. Saúde Pública. Saúde Coletiva.

\section{The RIGHT TO LIFE: CITIZENSHIP AND SOVEREIGNTY}

\begin{abstract}
this article aims to analyze the configuration of public in the health field, from a discussion about transformations that have allowed for passing from a public health discourse to a collective health discourse. the right to health is taken as the focus of the problematization of these transformations. the metamorphoses of public and their articulation with health have been grounded on the objectification of public as a device, along with conceptual operators of biopower, truth, and subjectivity. the configuration of public is here discussed from the right as response to a historical urgency and the type of game established between public health and collective health.
\end{abstract}

Key words: Device. Right. Public Health. Collective Health.

\footnotetext{
* Psicóloga. Doutora em Psicologia pela Pontifícia Universidade Católica do Rio Grande do Sul. Professora do Mestrado em Psicologia da Saúde da Universidade Católica Dom Bosco. Endereço: Universidade Católica Dom Bosco, Mestrado em Psicologia. Av. Tamandaré, 6000 - Jardim Seminário. CEP: 79117-900 - Campo Grande, MS - Brasil.

E-mail: anitabernardes@ig.com.br

$\star \star$ Psicóloga. Doutora em Educação pela University of Wisconsin-Madison. Professora adjunta da Pontifícia Universidade Católica do Rio Grande do Sul. Endereço: Pontifícia Universidade Católica do Rio Grande do Sul, Pró-Reitoria de Pesquisa e Pós-Graduação, Faculdade de Psicologia. Avenida Ipiranga, 6681, prédio 11, sala 930 - Partenon. CEP: 90619-900 - Porto Alegre, RS - Brasil.

E-mail:nmguares@pucrs.br
} 
É inútil determinar se Zenóbia deva ser classificada entre as cidades felizes ou infelizes. Não faz sentido dividir as cidades nessas duas categorias, mas em outras duas: aquelas que continuam ao longo dos anos e das mutações a dar forma aos desejos e aquelas em que os desejos conseguem cancelar a cidade ou são por esta cancelados (CALVINO, 1990, p. 36).

$\mathrm{O}$ artigo tem como objetivo analisar a questão do direito à saúde proposto pela Lei 8080 a partir de modificações no campo da saúde decorrentes da reforma sanitária no Brasil. A análise utiliza o público como um conceito-problema no campo da saúde, que ao ser modificado pela saúde coletiva, permite engendrar o aparecimento de outras regras de existência para objetos e sujeitos. Para tanto, o público é considerado como um dispositivo.

Isso significa uma discussão em que a questão do direito à saúde será problematizada como parte de um dispositivo, nomeado aqui de dispositivo de publicização. O dispositivo de publicização é uma forma de considerar uma ontologia do presente que coloca a existência em relação ao público. Desse modo, a questão sobre o que somos e no que estamos em vias de nos tornarmos é considerada a partir da relação que estabelecemos com as noções de público e privado. Não se trata de operar com uma relação binária: público e privado, mas de considerar a configuração de um dispositivo que forja essa oposição, ou seja, anexamos o público a um campo de racionalidade. Neste caso, não se parte do público como esfera, ou como atributo do Estado e sim como um território de experiência, de modo que outras formas de produção de sentido possam ser pensadas (FOUCAULT, 1999). O conceito de dispositivo (FOUCAULT, 1995) é operacionalizado de acordo com condições para demarcá-lo como tal: a) é uma rede que se estabelece entre um conjunto heterogêneo; b) trata-se de um tipo de jogo; c) é um tipo de formação em um momento histórico que responde a uma urgência. $\mathrm{O}$ conceito de dispositivo, então, é articulado às ferramentas foucaultianas de biopoder, verdade e sujeito para colocar em análise o direito à saúde.

Para pensar a questão do direito à saúde engendrada pelo dispositivo de publicização, circunscreve-se o campo da saúde coletiva mediante as diferenças que apresenta em relação à saúde pública. Essas diferenças dizem respeito não apenas à forma de objetivar a saúde, mas ao modo como o público vai modificando-se nesses jogos entre saúde pública e saúde coletiva. O discurso da saúde coletiva engendra-se a partir da década de setenta quando um movimento nomeado de reforma sanitária apresenta-se como uma forma de resistência no campo da saúde pública. Ou seja, em razão do aumento da precarização da vida ao passo que a indústria médica e farmacêutica crescia exponencialmente, é forjado um movimento que leva a redefinição da saúde como estratégia de diminuição das desigualdades sociais mediante a transformação das políticas em saúde que igualam saúde a condições de vida e direito à vida. A saúde passa a ser considerada um suporte social de filiação e possibilidade de vida. Dessa forma, a saúde pública ficou caracterizada como uma política que considerava a saúde enquanto corolário do desenvolvimento de um país, ou seja, a ênfase era dada ao desen- 
volvimento industrial/econômico e a saúde coletiva caracteriza-se como uma política em que saúde é direito à vida e indicador de desenvolvimento do país e não uma decorrência deste.

Este texto, em um primeiro momento, discutirá o direito como resposta a uma urgência histórica, de maneira a considerá-lo como potência política da vida. A partir disso, a reflexão volta-se para o tipo de jogo que se estabelece entre saúde pública e saúde coletiva e que coloca a vida no campo político. Essa discussão provoca o pensamento em direção a um conjunto heterogêneo que se estabelece em uma rede entre soberania, cidadania, alteridade e diferença. As considerações finais deste estudo voltam-se, então, para as políticas da existência no campo da saúde a partir de práticas que operam com o direito individual e a captura da potência política da cidadania.

\section{RESPOSTA A UMA URGÊNCIA HISTÓRICA: DIREITO COMO POTÊNCIA POLÍTICA DA VIDA}

A linha histórico-política, neste texto, toma a reforma sanitária como uma fissura na saúde pública, agenciada pelas próprias produções do público, por aquilo que o público conforma e que, ao mesmo tempo, lhe escapa. Para a construção dessa discussão, será utilizado um eixo de problematização: o público em relação ao direito. Essas formulações do público encontram suas condições de possibilidade na noção de saúde pública e saúde coletiva quando articuladas ao conceito de saúde.

O público coexistirá com o direito, a partir da compreensão de que um dispositivo não é em si um conjunto homogêneo, pois apresenta elementos que se reforçam, se antagonizam, se dispersam. Essa forma do público torna-se possível, justamente, na formação histórica que começa a desenhar-se no país e é ela mesma possibilidade para esta: a utopia de democratização do país, crise orgânica do Estado, movimentos sociais. Ou seja, apenas é possível articular-se em termos de movimentos sociais e de utopia de democratização quando novas formas de subjetividade são forjadas: é preciso que se produza um assujeitamento ao direito para que a resposta ao poder sobre a vida seja a potência política da vida, que, segundo Pelbart (2003, p. 83), "faz variar suas formas e reinventa suas coordenadas de enunciação".

O público de direto é uma forma produzida pelo dispositivo de publicização cujas características dizem respeito a considerar no campo da política a saúde como suporte social, ou seja, a saúde passa a ser objetivada pelo direito de acesso a bens sociais e materiais. Neste sentido, o público enquanto território existencial passa a articular-se ao direito à vida. Isso modifica a configuração do público quando de um território do dever, dever de desenvolvimento econômico, passa a engendrar um território do direito, direito à possibilidades de vida (BRASIL, 2001). Não se trata apenas de um dever, mas de um direito ou, nas palavras de Calvino (1990, p. 36), "aquelas (cidades) que continuam ao longo dos anos e das mutações a dar forma aos desejos e aquelas (cidades) em que os desejos conse- 
guem cancelar a cidade ou são por esta cancelados". O direito torna-se um mecanismo de luta política, uma possibilidade de vida quando equalizado à saúde, um conjunto de condições para a vida, uma potência de vida.

É por meio de um público de direito que se criam práticas de liberdade. Nesse sentido, o direito torna-se um princípio da possibilidade de democratização do País, bem como da saúde: não se trata apenas de a saúde ser um "direito fundamental"; ela tem que ser universal, com igualdade de acesso e qualidade de atenção para todos (BRASIL, 2001).

Esse processo de universalização e equidade da saúde é uma resposta política aos movimentos sociais que emergem na década de setenta e oitenta. Equalizar saúde ao direito e à igualdade apenas é possível em uma nação democrática, que opera com o público como uma questão de cidadania. Entram na ordem do discurso o público, o direito e a cidadania frente ao que o dever já colocava: a seguridade social. Ao estabelecer-se um Sistema de Seguridade Social como conjunto de ações de responsabilidade e de dever do Estado, articula-se o direito à saúde, à previdência e à assistência social (BRASIL, 2001). A seguridade social, quando formulada como uma questão de direito e tratando-se de uma rede entre saúde, previdência e assistência, precisa do sujeito cidadão, precisa do sujeito de direito. O direito publiciza a saúde como um suporte para a existência.

A reforma sanitária formula a saúde como "devendo ser conquistada pela população em suas lutas cotidianas, a objetiva tanto como um processo ativo e permanente - lutas diárias -, quanto derivado do acesso a suportes para a vida acontecer" (BRASIL, 1986, p. 382). O direito, então, será articulado à experiência de luta e de suporte. A diferença em relação às primeiras formulações da saúde pública diz respeito à experiência de propriedade. A propriedade, na saúde pública, estava colada à figura do privado, ou seja, a saúde era uma propriedade privada da indústria médica e do Estado. $\mathrm{O}$ acesso a ela se dava ou por meio da propriedade e dos meios de produção, ou pela relação de dependência/tutela dos bens do Estado mediante trabalho, sendo necessário filiar-se a um modo ou ao outro. A reforma sanitária retoma a questão do direito, mas a coloca em relação à propriedade social. A propriedade social é discutida por Castel (2003) como um conjunto heterogêneo de suportes sociais que tornam possível uma independência da propriedade privada, no sentido de deixar de ser propriedade de alguém (como na relação senhor/vassalo) ou de ter a propriedade de algo (meios de produção), mas que se caracterizam como "instancias sobre las que puede apoyar-se la possibilidade de desarollar estrategias individuales" (CASTEL, 2003, p. 19).

A questão que se coloca é: se o sujeito de direito é um artefato da publicização da saúde como um direito universal, que mecanismos produzem a experiência de um sujeito cidadão? Essa formulação encontra-se na relação entre público e cidadania. Diferentemente do que se encontrava na antigüidade clássica, em que cidadãos eram os homens-livres, ficando fora dessa categoria mulheres, crianças, escravos, estrangeiros e trabalhadores de subsistência, o cidadão, na contemporaneidade, passa a ser todo aquele que habita a geografia nacional. É uma forma de estabelecer a qualidade da relação entre o indivíduo privado e 
o Estado, quer dizer, migra-se da economia doméstica para a economia política: não se é mais o pai, a mãe, o filho, o marido, a esposa, etc., mas todo aquele que habita a nação e, por conta disso, estabelece uma outra relação com o Estado. Segundo Pinto (2004, p. 70):

A cidadania é uma noção que está historicamente ligada à idéia de Estado Nacional moderno e à noção de igualdade. Esta última condição é atribuída a todos os cidadãos independente de suas vidas privadas, profissão, religião, sexo, etc. E esta relação é uma relação de direitos e deveres, que não toma conhecimento se o indivíduo é homem ou mulher, se é mãe ou filha, casado, divorciado ou solteiro, se é culto ou inculto, alfabetizado ou analfabeto, se tem religião ou não. Portanto é uma relação que, em princípio, deve ser absolutamente igualitária.

Cidadania e igualdade como exercícios do sujeito de direito apresentam-se quando de um estado de dominação, como o da ditadura militar das décadas de sessenta e setenta, emergem práticas de liberdade produzidas, entre outros, pelo movimento da reforma sanitária. No campo da saúde, a saúde coletiva foi uma das formas de tornar móveis os fatos que impediam e cristalizavam as relações de poder por meio de procedimentos militares (FOUCAULT, 2004). A saúde coletiva enfrenta-se com a saúde pública mediante estratégias que estabelecem a saúde como uma questão de direito, como uma questão plural (BRASIL, 2001). A saúde, então, é tomada como um princípio de "redemocratização", torna-se necessária, como prática de governo, para mostrar que o País entrava em uma nova ordem social. Desse modo, foi fundamental colar saúde ao direito, pois era nessa operação que se tornava possível o sujeito experimentar-se como um cidadão, um sujeito de direitos que se dava a conhecer mediante um território público. $\mathrm{O}$ público de direito mobiliza o sujeito em relação ao Estado.

O mecanismo político é considerar um sujeito privado, uma existência privada que, ao relacionar-se com o Estado, ou seja, ao estabelecer uma existência pública, se apresenta como cidadão, cidadão de direitos. O poder sobre a vida é uma estratégia que pressupõe, agora, a relação entre o privado e o público por meio da cidadania. A luta política da saúde coletiva, no território da saúde pública, é tanto uma prática de liberdade, quando a saúde é um direito, quanto uma estratégia de governo para que o capital se reproduza. É preciso oferecer políticas para a "questão social", mas, como o personagem que emerge da ditadura militar é o militante dos movimentos sociais, as estratégias de governo precisam formular o cidadão, e não o tutelado. A expressão "questão social" é utilizada por Castel (1998, p. 30) para designar "uma aporia fundamental sobre a qual uma sociedade experimenta o enigma de sua coesão e tenta conjurar o risco de sua fratura". Aqui é utilizada para pensar a visibilidade da precariedade da vida da população brasileira. 
O cidadão é um efeito das práticas de liberdade que abrem espaço para ações refletidas. Essas práticas de liberdade, segundo Foucault (2004), são condições ontológicas da ética. Essas práticas de liberdade, quando articuladas ao campo da saúde, são formas de lutas contra o assujeitamento a certas formas de subjetivação produzidas pela saúde pública. São exercícios que colocam a população brasileira no campo do que Silva e Nardi (2005, p. 101) referem como "lutas contra as formas de assujeitamento que produzem a submissão e a serialização da subjetividade".

O público de direito agencia práticas de liberdade e cidadania. Isso significa uma ruptura no campo da saúde em que o público deixa de agenciar o sujeito público e passa a agenciar o sujeito cidadão. $\mathrm{O}$ direito formula uma tecnologia política, em que a biopolítica transforma a experiência de população enquanto sujeito público em experiência de cidadania como elemento constitutivo de um Estado democrático (FOUCAULT, 2004). O direito à vida é um direito à cidadania. As técnicas de governo das biopolíticas passam a operar segundo um conjunto específico de ações de cidadania. Essas práticas dão uma forma concreta à nova racionalidade política e à relação entre Estado e indivíduo. A cidadania produzida pelo público de direito apresenta uma utilidade política, pois promove a experiência de mudança na forma como o Estado posiciona-se em relação ao direito à vida. Nessa racionalidade, o outro do Estado seria a cidadania.

\section{TRATA-SE DE UM TIPO DE JOGO: A VIDA NO CAMPO POLÍTICO}

A necessidade que se cria de forjar subjetividades cidadãs engendra-se da visibilidade da "questão social" como questão de dever e de direito. Essa visibilidade da questão social frente ao agenciamento do dever e do direito constitui-se a partir de um campo de lutas que se efetuam de três maneiras: pelo assujeitamento, pela utilização e pela fixação do sujeito público. O assujeitamento diz respeito aos modos como o corpo do sujeito público torna-se propriedade do Estado e da medicina; a utilização refere-se ao modo pelo qual a objetivação do sujeito público é estratégica para o desenvolvimento econômico; a fixação ocorre quando o próprio sujeito público se fixa a si mesmo mediante estratégias de resistência. $\mathrm{O}$ sujeito público é uma forma de objetivação e subjetivação que torna uma existência objeto do Estado. O sujeito público configura-se como foco de investimentos no que tange a racionalidade de dever para com o desenvolvimento do país e de uma identidade nacional. O sujeito público é uma figura existencial que se conforma a partir de estratégias de governamentalidade voltadas para a população, cujos objetivos dizem respeito a tornar essa população administrável e rentável do ponto de vista do desenvolvimento econômico do país. É uma forma de produção característica da saúde pública.

Tomar a enunciação "a saúde é um direito fundamental do ser humano, devendo o Estado prover as condições indispensáveis ao seu pleno exercício" é considerar os jogos no campo da saúde que se estabelecem, se esgotam e se transformam em termos biopolíticos, agregando a lógica do direito à lógica do dever, a organização social ao corolário do desenvolvimento econômico. 
A conformação do público, nesse enfrentamento entre a saúde pública e a saúde coletiva, é herdeira de um território do outro desfiliado da propriedade privada, do outro trabalhador/família, do outro que não existe, mas que insiste - uma publicização que não objetiva um suporte social, uma propriedade social, uma inscrição em sistemas de proteção que permitam a vida acontecer (CASTEL, 2004). A biopolítica marca as diferenças de acesso às possibilidades de vida, utilizando-se da publicização, da territorialização do público para o poder se exercer e se justificar. Ao se colocar a vida no campo político e torná-la um capital do Estado, criou-se a própria possibilidade de esse capital do Estado transformar-se em capital de direito do ser humano.

O público, que marca vidas infames, acaba por vitalizá-las em sua potência política. Vitalizá-las porque as estratégias médico-assistenciais e tutelares do Estado, nos arranjos da saúde pública, esgotam-se em termos de custos e capacidade de assujeitamento. Mesmo com taxas de morbidades crescentes, a pobreza torna-se cada vez mais visível, pois o deixar morrer não é mais suficiente para torná-la opaca. Vitalizá-las porque a abrangência cada vez maior da utilização do sujeito público evidencia a precariedade da estratégia para o desenvolvimento econômico. Vitalizá-las porque o próprio sujeito público começa a fixar-se como potência política.

O público como território do tutelado produzido pela racionalidade assistencialista da saúde pública começa a metamorfosear-se, a alargar-se em: “o trabalho, a renda, a educação, o transporte, o lazer e o acesso aos bens e serviços essenciais". Essa ampliação da configuração do público no campo da saúde encontra-se com a racionalidade do direito "condições que assegurem acesso universal e igualitário às ações e aos serviços para a sua promoção, proteção e recuperação" (BRASIL, 1990).

Os efeitos dessa luta política voltam-se para o sujeito público e transformam a própria experiência que este faz de si: de sujeito assistido, torna-se um sujeito de direito - um sujeito de direito objetivado pelas problematizações da saúde:

Um campo de necessidade gerado pelo fenômeno saúdeenfermidade; a produção do serviço saúde com sua base técnica e material, seus agentes e instituições que são organizados para satisfazer essas necessidades; ser um espaço específico de circulação de mercadorias e de sua produção (empresas, equipamentos e medicamentos); ser um espaço de densidade ideológica; ser um espaço de hegemonia de classe através de políticas sociais que têm a ver com a produção social; possuir uma conquista tecnológica específica que permite solucionar problemas tanto a nível individual quanto coletivo. Aqui está tudo, a saúde vinculada ao político, social e econômico (FLEURY, 2005, informação verbal).

A visibilidade do coletivo começa a sair de uma região de opacidade por meio da formulação da saúde coletiva. O coletivo é uma resposta social frente às objetivações do público, ou seja, é preciso criar uma forma de diferenciação polí- 
tica: saúde pública e saúde coletiva. A publicização da saúde, ao criar um exército de tutelados mediante uma lógica assistencialista, acaba por dar visibilidade à precariedade da saúde dessas existências que toma como seu domínio. O público, ao colar-se à figura do Estado e aos desfiliados, retira a miséria humana de uma zona reservada. Esse aparecimento de uma zona que se encontrava em uma região reservada é uma contradição no dispositivo, e não um acidente no território, uma forma de redenção - constitui a própria lei de existência do público.

É a partir dessa lei de existência, ou de um conjunto de leis, que essa região passa a ser formulada pela saúde coletiva. Isso não serve para libertar o público de suas verdades, mas para alargar os mecanismos de poder que operam a publicização da saúde. É a forma pela qual o dispositivo apresenta um princípio de historicidade e um jogo político permanente.

O enfrentamento entre saúde pública e saúde coletiva manifesta-se no domínio da atenção à saúde, da institucionalização de certas formas práticas mediante o agenciamento do público. Desse modo, a territorialização do público, ao forjar a saúde pública como um fenômeno biopolítico, engendra as condições para aquilo que Foucault (2003) considera um movimento centrífugo, aquilo que escapa, de certa forma, às relações de poder: a saúde coletiva. O coletivo é tanto efeito do público quanto aquilo que o modifica em termos de estratégias políticas. Emergência de algo não como um termo do exterior, mas como um movimento que tenta se livrar do poder e, portanto, como aquilo que provoca cada novo desenvolvimento das capilaridades e redes de poder.

\section{UM CONJUNTO HETEROGÊNEO: SOBERANIA, CIDADANIA,}

\section{ALTERIDADE E DIFERENÇA}

A saúde coletiva torna-se possível, no dispositivo, na medida em que o dever e o direito se tornam leis de existência da saúde "A saúde é direito de todos e um dever do Estado" (BRASIL, 1990). O público operacionaliza-se mediante a relação com o dever e o direito, o que engendra uma descontinuidade no próprio território, pois do dever do Estado cria-se o seu avesso e o seu limite: a saúde como "um direito fundamental do ser humano". Passar do dever para o direito implicará um investimento biopolítico tanto na "questão social" que ganha visibilidade com o dispositivo, quanto nos personagens de quem se fala na correlação entre dever e direito - o sujeito soberano e o sujeito cidadão.

A questão está, então, em como o público de direito forja esse cidadão, na medida em que a saúde na década de setenta foi uma fonte de enriquecimento do capital privado. O enfrentamento entre saúde pública e saúde coletiva encontrase tanto com a saúde como saber - ausência de doença ou condições de acesso às possibilidades de vida -, quanto com a saúde como prática - de domínio do Estado ou de domínio da instituição médica. Como ausência de doença, a saúde é um direito das práticas em medicina, é um domínio médico; como possibilidades de vida, a saúde é um direito do cidadão, é uma questão de seguridade social, uma questão plural que envolve outras áreas além da medicina. 
A forma seria compor com ambas as formações - o público e o privado: "A lei do SUS regula, em todo o território nacional, as ações e serviços de saúde, executados isolada ou conjuntamente, em caráter permanente ou eventual, por pessoas naturais ou jurídicas de direito Público ou privadas" (BRASIL, 1990). Para tanto, a saúde passa a ser compreendida como um sistema que não se refere apenas aos órgãos do Estado, mas à parceria destes com "o setor privado contratado e conveniado, que interagem para o mesmo fim" (BRASIL, 2001, p. 300). Coloca-se um estreitamento das fronteiras entre público e privado. Então, a saúde será uma rede de ações que contemplam tanto os órgãos estatais quanto os órgãos privados, contudo, com uma operacionalidade única fundamentada nos princípios doutrinários e organizativos do SUS: universalização, equidade, integralidade, descentralização, hierarquização e participação popular.

O dispositivo de publicização agencia procedimentos por meio dos quais os indivíduos se tornam sujeitos cidadãos.

A "construção de cidadania" mediante tecnologias políticas torna-se uma condição para o governo da população vulnerável. Mas, para atingir a população, é preciso forjar sujeitos, produzir identidades, o que se engendra nos procedimentos de filiação e desfiliação ao dispositivo de publicização. Os processos de filiação e desfiliação organizam-se por meio de práticas despóticas e de cuidados que marcam e determinam o modo como os sujeitos se percebem, sentem, vivem. Rose (2001) entende as tecnologias despóticas como formas de controle de si mesmo, e tecnologias de cuidados de si como uma produção de si que não seja pelo controle ou pelo conhecimento. Publicizar a saúde torna-se um vetor de controle sobre o próprio indivíduo, e não apenas sobre a população. A filiação da população ao campo da saúde, por meio do dispositivo de publicização, assegura a possibilidade de coesão social. Entretanto, assegurar um modo de filiação não significa uma sobreposição do sujeito em relação às tecnologias de saúde, e sim uma subposição operatória auxiliar dos mecanismos de saúde.

É uma subposição operatória auxiliar na medida em que o outro, que agora se torna cidadão, sujeito de direitos, coloca em cena a produção de verdades sobre outridade e cidadania. $\mathrm{O}$ que não quer dizer o mesmo que constituição de alteridade, visto que, ao incluir, também exclui no momento em que as estratégias de inclusão tornam o outro um igual e se suprime a diferença. Tornar-se igual, ou constituir territórios identitários mediante codificações de cidadania e de direitos, produz um outro que não é o "ser-outro do outro" (TÉLLEZ, 2001, p. 78), mas um outro que deve ser equalizado pela reprodução do mesmo.

Dessa forma, apresenta-se a necessidade da figura do indivíduo privado para se estabelecer uma relação com o Estado em termos de cidadania, bem como a necessidade do setor privado como complementar as ações do Estado. Torna-se essencial para as biopolíticas na saúde operar com essa parceria. Isso implica a própria formulação do público de direito, pois o direito se constituirá também por enunciados de soberania e privilégios. São formas de subjetivação que se colam à figura do sujeito de direito. Foucault (2005, p. 43) analisa a relação entre a legislação do direito, as formas de soberania e mecânicas de poder correlatas: 
Temos, pois, nas sociedades modernas, a partir do século XIX até os nossos dias, de um lado uma legislação, um discurso, uma organização do direito público articulados em torno do princípio da soberania do corpo social e da delegação, por cada qual, de sua soberania ao Estado; e depois temos, ao mesmo tempo, uma trama cerrada de coerções disciplinares que garante, de fato, a coesão desse mesmo corpo social.

O que está em jogo são os direitos universais, os direitos civis, uma democracia, segundo Pinto (2004, p. 23), da pura liberdade do neoliberalismo: "as pessoas devem ser livres, devem ter garantidas suas liberdades e os governos devem garantir estas liberdades". Mas, como as liberdades trazem as diferenças, são necessárias políticas que utilizam a igualdade como forma de soterramento da diferença, da alteridade, por meio de práticas identitárias. Dessa forma o investimento será nos grupos constitutivos da população, ou seja, em comunidades a partir de critérios epidemiológicos.

A comunidade, como objeto de governo, de formas de governo, vem a ser utilizada por caracterizar-se de modo mais específico que a população. Segundo Mendes (2004), o tropo da população em comunidades ampara-se na heterogeneidade que os grupos representam dentro de uma população. A população caracterizava-se pelos fenômenos que a objetivavam: natalidade, moradia, habitação, mortalidade, etc. Assim, a noção de comunidade vem a demarcar a heterogeneidade da população como forma de controle. As comunidades são os diferentes grupos que conformam uma população; nas palavras de Mendes (2004, p. 58):

São vários os mecanismos de controle contemporâneo em torno das comunidades de risco, comunidades de rap, comunidades gays, comunidades de jogadores. Essas e outras comunidades identificam grupos de sujeitos sob os mais diversos objetivos para a conduta [...] contudo, essas conceituações e administrações, como também as comunidades a elas ligadas, não existem a priori; existem, sim, como invenções momentâneas que constantemente mudam de configuração e sentidos.

Nesse caso, as biopolíticas voltam-se para os grupos: saúde da mulher, saúde do trabalhador, DST/AIDS, usuários de drogas, adolescentes gestantes, entre outros, que vão desenhar comunidades. É nas comunidades que as biopolíticas forjadas pelo público do direito, passam a investir, visto que o conceito de saúde se amplia como condições e acesso a possibilidades de vida, e não mais apenas ausência de doença. Comunidade, aqui, é formada por coletivos da periferia, usuários e trabalhadores da rede pública de saúde que se tornam focos de estratégias políticas (controle e prevenção) e produção de conhecimento (epidemiologia e qualidade de vida). 
A questão que se coloca é que as práticas de liberdade que possibilitaram que esses coletivos aparecessem como sujeitos de direitos são capturadas no momento em que deixam de constituir-se como diferença, como alteridade, e tornam-se igualdade. Esse processo se dá na medida em que a alteridade passa a ser descrita e codificada, formulada dentro de um território de condutas, e não mais como um termo do exterior que modifica aquilo que a descreve.

\section{Políticas da EXISTÊnCIA}

O direito, na saúde coletiva, não está mais restrito ao exercício político do "voto" e da dependência do Estado, ou seja, o direito articula-se aos "Direitos Humanos Universais", relacionando o político, o civil e as condições de vida. Isso configura um campo de práticas que pulverizam o sujeito de direito em uma série de categorias, e a política sobre a vida irá investir sobre o elemento constitutivo da população.

Desse modo, o direito fragmenta o tecido social, e as ações serão específicas para cada agrupamento iluminado pelas estratégias biopolíticas, de maneira que o princípio de soberania do corpo social e de sua soberania ao Estado será operacionalizado em evidências individuais: o jovem será objetivado em relação à gravidez na adolescência, DST/AIDS, drogadição; a criança será objetivada pelo pré-natal, pela amamentação, pelo acesso à escolarização e controle do trabalho infantil; a mulher será objetivada como gestante, negra, índia, trabalhadora, etc. A fratura do tecido social encontra-se na diferença em termos de necessidades. A diferença diz respeito aos programas de saúde para os grupos constitutivos da população dependente do Estado: a multiplicação de cartões/bolsa sejam eles família, escola, cesta básica, e os incentivos para que o capital privado se reproduza: como na indústria farmacêutica e nos exames de alta tecnologia. $\mathrm{O}$ direito passa a conversar com o privilégio.

A soberania pressupõe uma indiferenciação entre os bens do Estado e os bens do indivíduo privado: tanto na tutela quanto nos subsídios estatais para a manutenção dos meios de produção privado. Como existência privada, deve-se ter o privilégio de acesso aos bens do Estado. Essa racionalidade captura o público no sentido da pura liberdade de mercado que minimiza o Estado, tornando-o apenas uma agência de fomento à iniciativa privada. Minimizar o Estado no que tange às políticas sociais justifica-se na lógica de excesso de direitos concedidos aos cidadão/comunidade, o que, numa formação capitalista, não se está mais disposto a conceder, na medida em que a garantia de direitos não é mais necessária para o capital se reproduzir. O que se produz como discurso é que o direito é um privilégio - "esta é a crise da cidadania, que chamo de crise por excesso, o cidadão tem direitos demais e as reformas do Estado estão indo na direção de diminuir estes direitos, que foram ressignificados nos discursos dos governos como privilégios" (PINTO, 2004, p. 73). Mas o privilégio é considerado para aqueles grupos dependentes dos suportes do Estado em termos de alimentação, escolarização, 
habitação, saúde. Os grupos que caracterizam o desenvolvimento tecnológico/industrial do país não são tomados como privilegiados, e sim como ocupados com o crescimento econômico, na medida em que contribuem com tributos.

O sujeito de direito produzido pelo dispositivo de publicização está colado também ao direito à propriedade privada; esse é o direito civil e político que se convencionou no liberalismo. Junto a isso, o sujeito dotado de direitos é uma objetivação jurídica, segundo Foucault (2004), um assujeitamento a aspectos mais formais de direitos individuais. Dessa forma, quando a saúde é formulada como direito à vida, nessa lógica, torna-se uma decorrência de direitos individuais e privados, na medida em que produz essa figura jurídica do sujeito de direito. Aquilo que possibilitou que a problemática do direito à vida aparecesse - a cidadania - é transformado em um objeto jurídico por meio de biopolíticas e investido em termos de propriedade privada por meio do assistencialismo.

O jogo é investir na lógica do direito individual para capturar a potência política da cidadania. Uma das formas de o direito individual recrudescer encontra-se nas práticas que vão engendrar essa conformação do público de direito, cujas estratégias se referem ao modo como o personagem "outro" é tomado no campo da saúde. Ou seja, a resposta que se dá à emergência da cidadania, das lutas de potências políticas, é a objetivação do outro como um sujeito de direitos ou não. Nessa formação, encontram-se maneiras de considerar, por exemplo, o usuário da rede de saúde como aquele que, além de ter privilégios demais, pois as biopolíticas são compensatórias (bolsa-família, bolsa-escola, cesta básica), não reconhece que tem acesso à saúde "gratuitamente". Dessa forma, ao posicionarse como cidadão quando se mobiliza em relação ao que tem direito - promoção, prevenção, cura e reabilitação da saúde -, o sujeito passa a ser tomado como um indivíduo privado pelo outro, um sujeito com privilégios demais que, portanto, não poderia reclamar pelo direito à vida sendo apenas beneficiário, e não parte da produção de riqueza.

Outro conjunto de práticas que operam com o sujeito de direito diz respeito ao modo como a instituição médica posiciona-se em relação ao SUS. Em uma articulação com os meios de comunicação de massa, as práticas médicas investem na fragilização do sistema de saúde. As ações são tanto no sentido da disponibilidade e envolvimento com a proposta de saúde sustentada pelo SUS em termos de integralidade, pois a medicina continua sendo um campo de especialidades, quanto na distorção da proposta de qualificação do SUS, como em nota publicada em um jornal por um grupo de sindicatos e associações médicas:

Nada indica que a superlotação do serviço (Emergência), onde diariamente mais de cem pessoas disputam 50 camas, vá ser alterada já que o número de leitos da nova unidade continuará o mesmo. Nos últimos 10 anos, os leitos públicos tiveram redução de $17 \%$ na Região Metropolitana, enquanto a população não parou de crescer. Paralelamente a isso, não foi implementada a Participação Complementar do SUS, com tabela adequada 
de remuneração dos serviços, mantida insuficiente até hoje e incapaz de induzir à ampliação das vagas nos hospitais. Ademais, na nova emergência a direção do GHC explicita um fato discriminatório: mulheres da Zona Norte de Porto Alegre e da Região Metropolitana ficarão sem atendimento ginecológico que há três décadas vinha sendo prestado à comunidade (CORREIO DO POVO, 19 abr. 2006, p. 7).

O jogo de força está no conjunto de regras de produção de verdades, quando se situa que é essencial o aumento de leitos hospitalares, que isso não acontece por uma inadequada tabela de remuneração e que existe uma ação discriminatória em termos de atenção frente a um trabalho que sempre foi prestado à população. A política de verdades que está em jogo opera tanto com o conceito de saúde produzido pela saúde pública - saúde como ausência de doença, com a forma de tratamento sendo médico-hospitalar, com aumento de leitos e exame ginecológico em emergências - quanto com o direito que a população tem a esses serviços - se ela aumenta, os serviços devem aumentar. O discurso toma o cidadão como um sujeito de direitos de acesso aos serviços médico-hospitalares. Atrelado a isso, ao que se coloca como fragilidade do sistema de saúde, aumenta o número de seguros de saúde privados ao se incitar uma figura de insegurança frente à possibilidade de acesso à saúde.

A política de insegurança que se engendra pelo dispositivo do público de direito é herdeira da noção de Estado mínimo e de enunciados sobre eficiência, competitividade, leis de mercado e privatizações. Captura o cidadão e torna-o um sujeito de direitos, um indivíduo privado na medida em que age nas existências individuais (COIMBRA, 2003).

O que ocorre é a forma como a saúde foi problematizada pelo público a partir de certo momento e de certos processos de vulnerabilidade decorrentes de uma racionalidade privada. A saúde, então, quando se torna um objeto do público, deixa de ser um conjunto de práticas de cuidados de si para o exercício político como discute Foucault (1985), como um dos elementos das artes de governo de si e do outro, para entrar em um território de regulação da vida no sentido de fazer viver ou deixar morrer. O público, assim, produz essa figura do indivíduo privado, e não do sujeito que se dá a conhecer por meio das relações de troca e filiação social. O público constitui-se como um território que filia o desfiliado à saúde, não em termos de práticas de liberdade, mas de práticas de recrudescimento da miséria humana. Isso porque o público não é um termo do exterior na relação com o privado - ele encontra neste sua possibilidade. A saúde coletiva emerge como um acontecimento no dispositivo, criando abalos na forma de territorialização da publicização da saúde. O direito enfrenta-se com o sujeito público, e multiplicam-se os personagens da saúde. Não é apenas a saúde que passa a ser uma questão plural, o sujeito da saúde também se pluraliza. Entretanto, essa possibilidade de configurar a saúde como um direito encontra-se com as formas de soberania produzidas pela publicização. O plural da saúde coletiva encontra o soberano da saúde pública, o que incita à formação de subjetividades tuteladas não apenas em relação à doença, mas, sobretudo, às condições de vida. $\mathrm{O}$ território de experiên- 
cia que se produz, ao mesmo tempo em que individualiza as condições de vida, torna-as dependentes, pois transforma práticas de liberdade em um termo capital de investimento e controle. O público não se interessa pela desfiliação, mas pela forma como o poder pode investir na desfiliação que funciona no interior do sistema político-econômico, ou seja, na sua rentabilidade e utilidade política.

O público, ou a publicização, é aquilo que dá condições de visibilidade e enunciabilidade à saúde e que, portanto, estabelece seus jogos de verdade e utilização. Esses jogos de verdade são tanto o instrumento que permite colocar a saúde em análise quanto um campo de produção de subjetividades no contemporâneo.

\section{REFERÊNCIAS}

BRASIL. Ministério da Saúde. Gestão Municipal de Saúde: textos básicos. Rio de Janeiro: Brasil. Ministério da Saúde, 2001.

Ministério da Saúde. $8^{a}$ Conferência Nacional de Saúde. Tema, Rio de Janeiro: ENSP/FIOCRUZ, v. 4, n. 7, ago. 1986. Anais.

Congresso. Senado. Lei no 8.080, de 19 de setembro de 1990. Dispõe sobre as condições para a promoção, proteção e recuperação da saúde, a organização e o funcionamento dos serviços correspondentes e dá outras providências. D.O.U. Diário Oficial da União; Poder Executivo, de 20 de setembro de 1990. Disponível em: <http://www.saude.inf.br/legisl/lei8080.htm>. Acesso em: 03 ago. 2005.

CALVINO, Í. As cidades invisíveis. São Paulo: Companhia das Letras, 1990.

CASTEL, R. As metamorfoses da questão social: uma crônica do salário. Petrópolis: Vozes, 1998. Topía, 2004.

Las Trampas de la exclusión: trabajo y utilidad social. Buenos Aires:

. Propriedad privada, propriedad social, propriedad de sí mismo. Rosario: Homo Sapiens, 2003.

COIMBRA, B. C. Historicizando a relação entre psicologia e direitos humanos. In: JACÓ-VILELA, A. M.; CEREZZO, A. C.; RODRIGUES, H. B. C. (Org.). Paradigmas - historiografia, psicologia, subjetividade. Rio de Janeiro: ReluméDumará/FAPERJ, 2003. v. 1, p. 235-246.

CORREIO DO POVO. Porto Alegre: Caldas Júnior, p. 7, 19 abr. 2006.

FLEURY, S. Palestra de abertura das atividades acadêmicas da Fundação Oswaldo Cruz. Rio de Janeiro: FIOCRUZ, 2005. 
FOUCAULT, M. História da sexualidade III: o cuidado de si. Rio de Janeiro: Graal, 1985.

. Microfisica do Poder. Rio de Janeiro: Graal, 1995.

1999.

. História da sexualidade I: a vontade de saber. Rio de Janeiro: Graal.

. Poder e Saber. In.

. Ditos e escritos IV. Rio de Janeiro: Forense

Universitária, 2003. p. 223-240.

. Ditos e escritos V. Rio de Janeiro: Forense Universitária, 2004.

. Em defesa da sociedade. São Paulo: Martins Fontes, 2005.

MENDES, C. Controla-me que te governo: os jogos para computador como formas de subjetivação e administração do "eu". 2004. Tese (Doutorado em Educação)-Faculdade de Educação, Universidade Federal do Rio Grande do Sul, Porto Alegre, 2004.

PELBART, P. P. Vida Capital: ensaios de biopolítica. São Paulo: Iluminuras, 2003.

PINTO, C. Teorias da democracia: diferenças e identidades na contemporaneidade. Porto alegre: EDIPUCRS, 2004.

ROSE, N. Como se deve fazer a história do Eu?. Educação \& Realidade, Porto Alegre, v. 26, n. 1, p. 33-57, jan./jun. 2001.

SILVA, R. N.; NARDI, H. C. Ética e subjetivação: as técnicas de si e os jogos de verdade contemporâneos. In: GUARESCHI, N.; HUNING, S. (Org.). Foucault e a psicologia. Porto Alegre: Abrapso Sul, 2005. p. 93-105.

TÉLLEZ, M. A paradoxal comunidade por-vir. In: LARROSA, J.; SKLIAR, C. (Org.). Habitantes de Babel: políticas e poéticas da diferença. Belo Horizonte: Autêntica, 2001. p. 45-78.

Recebido em: outubro de 2007

Aceito em: março de 2008 